\title{
Evaluation of the Effect of Hydroalcoholic Extracts of Cassia Occidentalis Leaves in Neutrophil Adhesion Test in Rats
}

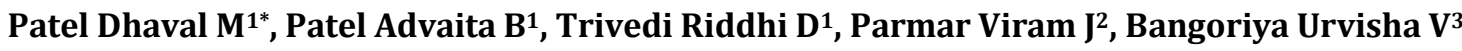 \\ ${ }^{1}$ SAL Institute of Pharmacy, Opp-Science city, Ahmedabad-380060, Gujarat, India \\ ${ }^{2}$ K. V. Virani Institute of Pharmacy \& Research Centre, Badhda, Amreli, Gujarat, India \\ ${ }^{3}$ Drug Inspector, Food and Drug Administration, Gujarat, India
}

\begin{abstract}
Evaluation of the effect of hydroalcoholic extracts of Cassia occidentalis leaves in neutrophil adhesion test in Rats. The effect of oral administration of hydroalcoholic extract of Cassia occidentalis leaves on neutrophil has been studied and is compared with control group on rats. The differential leukocyte count (DLC) was performed by fixing the blood smears and staining with leucofine and percent neutrophils in each sample was determined. After the initial counts, blood samples were incubated with $80 \mathrm{mg} / \mathrm{ml}$ of nylon fibers for $10 \mathrm{~min}$ at $37^{\circ} \mathrm{C}$. Supplementation with hydroalcoholic extract of Cassia occidentalis leaves significantly decreased neutrophil adhesion. The results indicate that the leaf of Cassia occidentalis is endowed with protected neutrophil adhesion. These effects could conclude that Cassia occidentalis has an antiasthmatic property.
\end{abstract}

Keywords: Cassia occidentalis, Neutrophil adhesion, analysis of variance

Article Info: Received 10 July 2019; Review Completed 12 Aug 2019; Accepted 18 Aug 2019; Available online 25 August 2019

Cite this article as:

Patel DM, Patel AB, Trivedi RD, Parmar VJ, Bangoriya UV, Evaluation of the Effect of Hydroalcoholic Extracts of Cassia Occidentalis Leaves in Neutrophil Adhesion Test in Rats, Journal of Drug Delivery and Therapeutics. 2019; 9(4-s):12181221 DOI: http://dx.doi.org/10.22270/jddt.v9i4-s.3940

*Address for Correspondence:

Dhaval M Patel, SAL Institute of Pharmacy, Opp-Science city, Ahmedabad-380060, Gujarat, India

\section{INTRODUCTION}

Respiratory diseases are second to cancer as the causes of death and disability to adults. Acute respiratory infection, tuberculosis and chronic obstructive pulmonary disease rank third, fourth and fifth respectively as per the global health situation. ${ }^{1}$

According to a survey in UK in the year 2008, respiratory diseases occupied 15\% among all other diseases. Asthma is the commonest disease in children in economically developed countries and it is also common in adults and it is increasing in prevalence and severity. Around 275 million people around the globe suffer from asthma and this number is rising worldwide, deaths from this condition have reached 18 million annually. The number of deaths from asthma also has risen in the United States. The WHO says about five thousand Americans die from asthma attacks each year. In the early 1980s, the yearly death rate from asthma in the United States was about half of that.

Bronchial asthma is a complex disease with several clinically well-defined pathogenic components, including recurrent reversible airway obstruction, chronic airway inflammation and development of airway hyperresponsiveness. ${ }^{2}$ Airway inflammation is the primary problem in asthma. An initial event in asthma appears to be the release of inflammatory mediators (e.g., histamine, tryptase, leukotrienes and prostaglandins) triggered by exposure to allergens, irritants, cold air or exercise. The mediators are released from bronchial mast cell, alveolar macrophages, T- lymphocytes and epithelial cells. Some mediators directly cause acute bronchoconstriction, termed the "early-phase asthmatic response". The inflammatory mediators also direct the activation of eosinophils and neutrophils, and their migration to the airway, where they cause injury. This is called "late-phase asthmatic response" results in epithelial damage, airway edema, mucus hypersecretion and hyperresponsiveness of bronchial smooth muscle. Varying airflow obstruction leads to recurrent episodes of wheezing, breathlessness, chest tightness, and cough. ${ }^{3}$ Based on clinical trial grounds and measurement of IgE, there are 2 major types of asthma. 1) Extrinsic asthma (atopic asthma) in which symptoms develops only on exposure to a specific allergen. Extrinsic asthmatics rarely suffer from status 
asthmatics and require infrequent medication. 2) Intrinsic asthma (perennial) in which the symptoms are precipitated by infection, frequency of status asthmatics is higher and no allergic aetiology is detectable. Both these types behave differently to anti asthmatics drugs. Mixed features of both the types may be seen in some patients. ${ }^{4}$

The gross pathology of asthmatic airway display lung hyperinflation, smooth muscle hypertrophy, lamina reticularis thickening, mucosal edema, epithelial cell sloughing, cilia cell disruption, and mucus gland hypersecretion. Microscopically, asthma is characterized by presence of increased number of eosinophils, lymphocytes, and plasma cells in the bronchial tissues, bronchial secretion, and mucus. Initially, there is recruitment of leukocytes from the bloodstream to the airway by activated CD4 T-lymphocytes also direct the release of inflammatory mediators from eosinophils, mast cells, and lymphocytes. In addition, the subclass 2-helper T-lymphocytes subset of activated T-lymphocytes produces IL-4, IL-5, and IL-13. IL-4 in conjugation with IL-13 signals the switch from IgM to IgE antibodies. The cross linkage of two IgE antibodies molecules by allergen causes mast cells to degranulate; releasing histamine, leukotrienes, and other mediators that perpetuate the airway inflammation. IL-5 activates the recruitment and activation of eosinophils. The activated mast cells and eosinophils also generate their cytokines that help to perpetuate the inflammation.

Regardless of the triggers of asthma, the repeated cycles of inflammation in the lung with injury to the pulmonary tissues followed by repair may produce long term structural changes ("remodeling") of the airways. ${ }^{5}$

Bronchial asthma is major public health problem worldwide, and the morbidity and mortality of asthma have increased in past few decades. Between 100-150 million people around the global roughly the equivalent of the population of the Russian Federation suffers from asthma and this numbers is rising. Worldwide, death from this condition have reached over 1, 80,000 annually. India has estimated 15-20 million asthmatics. In India, rough estimates indicate a prevalence of between $10-15 \%$ in 5-11 years old children. 6 The health burden of asthma is increasing globally at an alarming rate, providing a strong impetus for the development of new therapeutics.

The world health organization (WHO) has recognized herbal medicine as an essential building block for primary health care of vast countries like India and China. India is perhaps the largest producer of medicinal herbs and is rightly called the "botanical garden of the world". There are very few medicinal herbs of commercial importance, which are not collected or cultivated in this country. Medicinal herbs have been in use for thousands of years, in one form or another, under the indigenous system of medicine like Ayurveda, Siddha, and Unani. Since independence in 1947, India has made tremendous progress in agro technology, process technology, standardization, quality control, research and development. Large numbers of herbs are being used for the treatment and prophylaxis of asthma since ancient time, however systemic studies that identify all possible mechanism of each and every herbal antiasthmatic drug are lacking.

Asthma is a disease characterized by redcurrant of reversible airway obstruction with attack of wheeze, shortness of breath and often nocturnal cough. Essential features of asthma are airway inflammation which causes bronchial hyper responsiveness which in turn results in recurrent reversible airway obstruction. There are various causative factors for asthma like allergens, drugs induced asthma, cold air, irritant chemicals etc.

Various allopathic drugs like corticosteroids, anticholinergics, mast cell stabilizers leukotriene antagonists, $\beta_{2}$ receptor agonist etc., are in use for the treatment for asthma. In the most extents, these drugs have been helpful in the symptomatic relief, treatment and prophylaxis of asthma. But the involvement of debilitating side effects is major drawback of these drugs. For example, long-term treatment with corticosteroids leads osteoporosis, skeletal muscle myopathy, obesity etc. ${ }^{7}$

As a result of problems in asthma, there is high prevalence of usage of alternative traditional of medicines for the treatment of asthma. Ayurveda offers a unique insight into comprehensive approach to asthma management through proper care of respiratory tract. More than 400 medicinal plant species have been used ethnologically and traditionally to treat the symptoms of asthmatics, other allergic and autoimmune disorders worldwide. The world health organization (WHO) has recognized herbal medicine as an essential building block for primary health care of vast countries like India and China. India is perhaps the largest producer of medicinal herbs and is rightly called the "botanical garden of the world". There are very few medicinal herbs of commercial importance, which are not collected or cultivated in this country. Medicinal herbs have been in use for thousands of years, in one form or another, under the indigenous system of medicine like Ayurveda, Siddha, and Unani. Since independence in 1947, India has made tremendous progress in agro technology, process technology, standardization, quality control, research and development. Large numbers of herbs are being used for the treatment and prophylaxis of asthma since ancient time, however systemic studies that identify all possible mechanism of each and every herbal antiasthmatic drug are lacking. So many herbal drugs are used in treatment of bronchospasm. Mostly used herbal drugs are Curcuma longa, C. gigantia, Indigofera tinctoria, Asystasia gangetica, Bryonia laciniosa etc. Options available today have many limitations including risk of adverse effects, where as herbal world offers many options with safety, efficacy \& availability with economical aspects also. Cassia occidentalis, commonly known as "Kasundri", is one of the leading drugs used as alternative system of treatments. As per traditional method, it is known for its expectorant activity.

In light of this, the objective of the study is to evaluate the effect of hydroalcoholic extracts of Cassia occidentalis in neutrophil adhesion test.

\section{MATERIALS AND METHODOLOGY}

\section{Preparation of extract:}

Leaves of Cassia occidentalis were collected and properly cleaned and dried under shade to remove excess of moisture. The dried plant material was then subjected to size reduction to coarse powder and passed the powder from sieve no. 40 . About $500 \mathrm{gm}$ of air dried powder of leaves of Cassia occidentalis were extracted in soxhlet with 20:80 ethanols:water hydroalcoholic mixture in soxhlet apparatus by continuous hot extraction. After each extraction, the solvent was recovered using distillation assembly, and the both extracts were concentrated. The extracts were preserved in air tied container for experiment.

\section{Animal selection:}

Healthy adult Albino Wistar rats of either sex were used for this study. They were housed at ambient temperature $\left(22 \pm 1^{\circ} \mathrm{C}\right)$, relative humidity $(55 \pm 5 \%)$ and $12 \mathrm{~h} / 12 \mathrm{~h}$ light 
dark cycle. Animals had free access to standard pellet diet and water given ad libitum. The protocol of the experiment was approved by the Institutional Animal Ethical Committee (IAEC) as per the guidance of the Committee for the Purpose of Control and Supervision of Experiments on Animals (CPCSEA), Ministry of Social Justice and Empowerment, Government of India.

\section{Neutrophil adhesion test ${ }^{8-9}$}

The study was carried out as described by Wilkinson PC \& Ghule BV et al. Albino wistar rats of either sex were used for the study. The animals were randomly divided in three groups $(n=6)$ and treated accordingly. Duration of treatment was 14 days.

\section{Group I: Control (treated with vehicle, p.o.)}

Group II: Hydroalcoholic extract of C. occidentalis leaf (HECL) $(100 \mathrm{mg} / \mathrm{kg}$, p.o.)

Group III: Hydroalcoholic extract of $C$. occidentalis leaf (HECL) (200 mg/kg, p.o.)

On day 14, blood samples were collected from the retro orbital plexus into heparinized vials and analyzed for total leukocyte count (TLC). The differential leukocyte count (DLC) was performed by fixing the blood smears and staining with leucofine and percent neutrophils in each sample was determined. After the initial counts, blood samples were incubated with $80 \mathrm{mg} / \mathrm{ml}$ of nylon fibers for $10 \mathrm{~min}$ at $37^{\circ} \mathrm{C}$. The incubated blood samples were again analyzed for TLC and DLC. The product of TLC and percent neutrophils gave the neutrophil index of blood sample.

$\%$ neutrophil adhesion was calculated from the following formula:

$$
\text { Neutrophil adhesion }(\%)=\frac{\text { NIu }- \text { NIt }}{\text { NIu }} \times 100
$$

Where, $\mathrm{NIu}=$ Neutrophil index of untreated blood sample

$$
\text { NIt= Neutrophil index of treated blood sample }
$$

\section{Statistical analysis:}

Results were expressed as mean \pm SEM. Differences among data were determined using one-way ANOVA followed by Student-Newman-Keul's test (Graphpad Prism software for Windows, Version 4.10.1998). Differences between the data were considered significant at $P<0.05$.

\section{RESULTS AND DISCUSSIONS}

Mucosal inflammation is associated with an increase in the expression of vascular and leucocyte adhesion molecules.1011 A number of cellular adhesion molecules are involved in the adhesion of neutrophils to the site of tissue inflammation. Neutrophils must adhere to the endothelium and subsequently migrate through the vessels before entering the tissue. Neutrophil rolling and arrest on endothelium is mediated through successive interactions of selectins and $\beta$-integrins. ${ }^{12}$ Neutrophil adhesion to endothelium is enhanced by activation of adenosine Acompartments. ${ }^{13}$ Subsequent adhesion to apical epithelial membranes results in activated neutrophils persisting in crypt abscesses with local release of chemotactic and chemoactivating substances. ${ }^{14-15}$ In addition to producing a number of functionally diverse substances, polymorphonuclear cells also express receptors for a number of mediators including IL-8, IL-9 and the high-affinity IgE receptor.16-17 These receptors have been implicated in different inflammatory reactions, including allergic asthma. Neutrophil recruitment from the circulation into the interstitium during inflammation is an extension of a physiological process across an adapted, permissive cell layer. Such transmigration involves the tethering, rolling, tight adhesion, and diapedesis of marginalised flowing cells. ${ }^{18}$ Neutrophil adhesion to the vascular endothelium as described in the 'traffic signal' paradigm, results from the sequential recruitment of selectins, $\beta_{221}$ receptors. Binding to the adenosine $A_{2}$ receptor results in inhibition of the respiratory burst reaction and decreased binding to fibrinogen. ${ }^{19-22}$ The percentage of neutrophil adhesion was estimated on day 14. Pretreatment with HECL at dose 100 and $200 \mathrm{mg} / \mathrm{kg}$, p.o. induced a significant $(p<0.001)$ decrease in the in vitro neutrophil adhesion to nylon fibers with respect to that of control group, which correlated the decrease in percentage of neutrophils. However, HECL at dose of $100 \mathrm{mg} / \mathrm{kg}$ did not show any significant change in neutrophil adhesion when compared with respective control group. Thus hydroalcoholic extract of leaves of Cassia occidentalis Linn. reduced significantly percentage of neutrophil adhesion. This may help in decreasing the release of various cytokines and might be binding to $A_{1}$ and/or $A_{2}$ receptor on endothelium and results in producing antiinflammatory action. (Table 1, Figure 1)

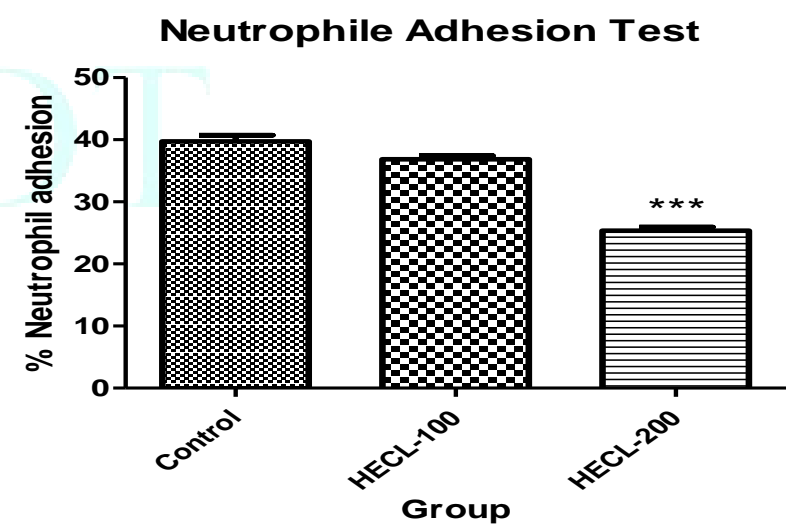

Figure 1: Effect of hydroalcoholic extract of Cassia occidentalis leaves on Neutrophil adhesion test in rats

Table 1 Effect of hydroalcoholic extract of Cassia occidentalis leaves on Neutrophil adhesion test

\begin{tabular}{|c|c|c|c|c|}
\hline \multirow{2}{*}{ Group } & \multirow{2}{*}{$\begin{array}{c}\text { Dose } \\
\text { ( } \mathbf{m g} / \mathbf{k g})\end{array}$} & Untreated blood & Fiber treated blood & \multirow{2}{*}{$\begin{array}{c}\text { Neutrophil adhesion } \\
\text { (\%) }\end{array}$} \\
\cline { 3 - 5 } & - & $334017 \pm 20021$ & $202343 \pm 15303$ & $39.71 \pm 1.01$ \\
\hline Control & 100 & $640034 \pm 24571$ & $403944 \pm 14655$ & $36.85 \pm 0.58$ \\
\hline HECL & 200 & $432946 \pm 18191$ & $322892 \pm 12555$ & $25.37 \pm 0.57^{* * *}$ \\
\hline
\end{tabular}

Values are Mean \pm SEM $(\mathrm{n}=6)$; analyzed by one way ANOVA followed by Turkey's multiple comparison test, ${ }^{* * *} p<0.001$ for change difference Vs control group. 


\section{CONCLUSION}

In conclusion, the presented data indicate that administration of the hydroalcoholic extract of Cassia occidentalis leaves to rats reduced the neutrophil aadhesion, supporting folk information regarding antiasthmatic activity of the plant. The mechanism underlying this effect is still unknown, but is apparently related to reduction in neutrophil adhesion. These effects could conclude that Cassia occidentalis has an antiasthmatic property.

\section{REFERENCES}

1. http://google/WHO, 1998.

2. Kay AB. Asthma and inflammation. J Allergy Clin immunol. 1991; 87: 893-910.

3. Bethesda. NHLBI: National Asthma Education and Prevention Program, Expert Panel report 2, Guidelines for the diagnosis and management of Asthma. NIH Publication. 1997; 97: 4051.

4. Barar FSK. Drugs acting on respiratory system. In: Essentials of Pharmacotherapeutics. $3^{\text {rd }}$ edition. 2003; 544-552.

5. Fireman P. Understanding asthma Pathophysiology. Allergy Asthma Proc. 2003; 24 (2): 79-83.

6. http:// www.google/ WHO fact sheet, 2000.

7. Walker R, Edwards C. Clinical pharmacy and therapeutics. $2^{\text {nd }}$ edition. 1999: 351-365.

8. Wilkinson PC. Neutrophil adhesion test. In: Vane JK, Ferreria SH (Eds.), Handbook of Experimental Pharmacology, first ed. Springer Verlag, Berlin. 1978: 109.

9. Ghule BV, Murugananthan G, Nakhat PD, Yeole PG Immunostimulant effects of Capparis zeylanica Linn. leaves. Journal of Ethnopharmacology. 2006; 108: 311-315.

10. Balsitis M, Morrell K, Mahida Y, Hawkey CJ. Cell adhesion molecule expression by colonic mucosa in ulcerative colitis. Eur J Gastroenterol Hepatol. 1994; 6: 351-358.

11. Dippold W, Wittig B, Schwaeble W, Mayet W, Buschenfelde M. Expression of intercellular adhesion molecule 1 (ICAM-1, CD54) in colonic epithelial cells. Gut. 1993; 34: 1593-1597.
12. Susan CF, Qutayba H. Images in allergy and immunology: neutrophils in asthma. Journal of Allergy and Clinical Immunology. 2007; 119: 1282-1286.

13. Madara JL. Migration of neutrophils through epithelial monolayers. Trends in Cell Biology. 1994; 4: 4-7.

14. Nathan CF. Neutrophil activation on biological surfaces: massive secretion of hydrogen peroxide in response to products of macrophages and lymphocytes. J Clin Invest. 1987; 80, 15501560.

15. Opal SM, Palardy JE, Marra MN, Fisher CJ, McKelligon BM, Scott RW. Relative concentrations of endotoxin binding proteins in body fluids during infection. Lancet. 1994; 344: 429-431.

16. Soussi-Gounni A, Koussih L, Nutku E, Lamkhioued B, Nicolaides NC, Levitt RC. Functional expression of IL-9 receptor by human neutrophils from asthmatic donors: role in IL-8 release. Journal of Immunology. 2001; 166: 2768-2774.

17. Soussi-Gounni A, Lamkhioued B, Koussih L, Ra C, Renzi PM, Hamid Q. Human neutrophils express the high-affinity receptor for immunoglobulin E (Fc epsilon RI): role in asthma. FASEB J. 2001; 15: 940-949.

18. Adams DH, Shaw S. Leucocyte-endothelial interactions and regulation of leucocyte migration. Lancet. 1994; 343: 831-836.

19. Prescott SM, Zimmerman GA, McIntyre TM. Platelet activating factor. J Biol Chem. 1982; 1990 (17): 381-384.

20. Dianzani C, Brunelleschi S, Viano I, Fantozzi R. Adenosine modulation of primed human neutrophils. European Journal of Pharmacology. 1994; 263: 223-226.

21. Cronstein BN, Levin RI, Philips M, Hirschhorn R, Abramson SB, Weissman G. Neutrophil adherence to endothelium is enhanced via adenosine $A_{1}$ receptors and inhibited via adenosine $A_{2}$ receptors. Journal of Immunology. 1992; 148: 2201-2206.

22. Meenan J, Mevissen M, Monajemi H, Radema SA, Soule HR, Moyle M, Tytgat GNJ, van Deventer SJH. Mechanisms underlying neutrophil adhesion to apical epithelial membranes. Gut. 1996; 38: 201-205 